\title{
Post Total Thyroidectomy, Isolated Right Side Chylothorax with High Output Fistula Managed with Lymphangiography
}

\author{
Dhruva Sharma, Deven Juneja, Omender Singh, Amit Goel, Prashant Singh, Varun Arora \\ Institute of Critical Care Medicine, Max Super Speciality Hospital, Saket, New Delhi, India
}

\section{Abstract}

Chylothorax is a rare complication after total thyroidectomy with radical neck dissection, and isolated right side chylothorax is even rarer. Treatment may be conservative or surgical. Besides being helpful in making a diagnosis, thoracic duct lymphangiography (TDL) may be therapeutic in some cases. However, its application in high output chylous leak is not fully explored. Here, we present a rare case of right-sided high output chylothorax, secondary to total thyroidectomy, successfully treated with TDL.

Keywords: High outflow chylothorax, right side chylothorax, thoracic duct lymphangiography

\section{INTRODUCTION}

Total thyroidectomy is generally associated with hypothyroidism, hypocalcemia, hematoma, and recurrent laryngeal nerve injury as its most common complications. One of the uncommon complications is chylous leak, which is associated with lateral neck dissection and may occur on one side or on both sides, with a reported incidence of $5.1 \%$ and $6.2 \%$, respectively. ${ }^{[1]}$ Rarely, it further complicates into chylothorax. Chylothorax after thyroidectomy mostly depends on the approach of surgery, with the reported incidence of $1.85 \%$ and $7.3 \%$ with cervical or thoracic approach, respectively. ${ }^{[1]}$ A typical patient of chylothorax is a middle-aged female with a diagnosis of thyroid carcinoma who has undergone lateral neck dissection. Thoracic duct lymphangiography (TDL), an old invasive radiological technique, may help in the detection of chylous fistulas and occlusion in some cases and has also been used therapeutically when the conservative management has failed. It may also help in deciding the further plan of management in high drain output chylothorax.

\section{Case Report}

A 35-year-old female, a diagnosed case of papillary carcinoma of thyroid, underwent total thyroidectomy with radical neck and mediastinal lymph node dissection. Postoperative period was uneventful, with not much chylous drainage from the neck drain, which was removed on postoperative day 4 , and

\begin{tabular}{|l|l|}
\hline \multicolumn{2}{|c|}{ Access this article online } \\
\hline Quick Response Code: & Website: \\
\hline & www.ijrc.in \\
\hline & \\
\hline
\end{tabular}

she was discharged from the hospital. She was apparently asymptomatic for 2 weeks. However, gradually she started developing breathlessness for which she was readmitted.

$\mathrm{X}$-ray chest showed right-sided pleural effusion, for which an intercostal drain was placed, which drained milky white fluid [Figure 1]. After 2-3 days with no clinical improvement and deteriorating condition, she got transferred to the intensive care unit (ICU), where due to severe respiratory distress, she was intubated and put on invasive mechanical ventilation. Initially, drain output was high with $2400 \mathrm{ml}$ on day 1 , followed by $2000 \mathrm{ml}$ on day 2 and $1980 \mathrm{ml}$ on day 3 . As she was hemodynamically unstable, vasopressors were started after aggressive fluid resuscitation. Screening two-dimensional echocardiography showed pericardial effusion, $1.5 \mathrm{~cm} \times 2 \mathrm{~cm}$ at the apex with impending cardiac tamponade. Emergency cardiocentesis was done, and 200 $\mathrm{ml}$ fluid was drained. The pleural and pericardial fluid analysis showed triglycerides of $334 \mathrm{mg} / \mathrm{dl}$ and $51 \mathrm{mg} /$ $\mathrm{dl}$, respectively, with serum triglyceride being $129 \mathrm{mg} / \mathrm{dl}$.

Address for correspondence: Dr. Dhruva Sharma, Institute of Critical Care Medicine, Max Super Speciality Hospital, Saket, New Delhi, India. E-mail: dhruvasharma1987@gmail.com

This is an open access journal, and articles are distributed under the terms of the Creative Commons Attribution-NonCommercial-ShareAlike 4.0 License, which allows others to remix, tweak, and build upon the work non-commercially, as long as appropriate credit is given and the new creations are licensed under the identical terms.

For reprints contact:WKHLRPMedknow_reprints@wolterskluwer.com

How to cite this article: Sharma D, Juneja D, Singh O, Goel A, Singh P, Arora V. Post total thyroidectomy, isolated right side chylothorax with high output fistula managed with lymphangiography. Indian J Respir Care 2021;10:249-51.

Received: $15-08-2020$ Accepted: $27-09-2020$
Revised: 06-09-2020 Published: 14-06-2021 


\section{Sharma, et al.: Right side chylothorax, lymphangiography}

Laboratory parameters showed thyroid-stimulating hormone of $120 \mathrm{mcg} / \mathrm{dl}$ with low total serum calcium levels [Table 1]. Tablet thyroxine was started in addition to calcium infusion with 12 hourly serum calcium level monitoring. A computed tomography scan of the chest was done on day 2, which showed an extensive area of consolidation in the right lower lobe. She was started on broad-spectrum antibiotics empirically and fat-free diet. On day 4, TDL was done to check



Figure 1: Chest X-ray showing right side isolated chylothorax (prelymphangiography) the chyle fistula site and to plan future surgical management in view of high output chylothorax.

On day 6, her pleural drain decreased to $300 \mathrm{ml}$. She was extubated successfully, and the pericardial drain was also removed. She was shifted out of ICU on day 8 and discharged home on day 11 [Figure 2].

\section{Discussion}

Total thyroidectomy and modified neck dissection can sometimes lead to chyle fistula formation, which may lead to rare complications such as chylothorax and respiratory distress. It may occur during surgery or due to mechanical obstruction because of back pressure from thoracic duct ligation, which often is noticed after postoperative day $5 .{ }^{[1]}$

Bilateral and left side chylothorax has been reported. However, isolated right side chylothorax with chylous-pericardial effusion in postoperative case of carcinoma thyroid has never been reported, as per our knowledge. ${ }^{[1]}$ Although chylous pericardial effusion is a rare complication, it can be associated with severe hypothyroidism, which was present in our patient.

Conservative management is always the first treatment modality, followed by interventional radiology and surgical measures. ${ }^{[2]}$ Conservative measures include a reduction in

Table 1: Sequential laboratory investigation

\begin{tabular}{|c|c|c|c|c|c|c|c|c|c|c|}
\hline & Day 1 & Day 2 & Day 3 & Day 4 & Day 5 & Day 6 & Day 7 & Day 8 & Day 9 & Day 10 \\
\hline Hemoglobin (g/dL) & 13.2 & 12.7 & 8 & 10.9 & 8.9 & 9.8 & 10.3 & 11.3 & 10.5 & 9.8 \\
\hline $\operatorname{TLC}\left(10^{9} / \mathrm{L}\right)$ & 17.4 & 10.5 & 9.5 & 17.5 & 12.5 & 8.9 & 9.5 & 10.6 & 9.2 & 8 \\
\hline Platelet $\left(10^{9} / \mathrm{L}\right)$ & 197 & 199 & 170 & 168 & 181 & 220 & 264 & 357 & 397 & 371 \\
\hline Sodium $(\mathrm{mmol} / \mathrm{L})$ & 148 & 145 & 140 & 142 & 145 & 140 & 139 & 134 & 136 & 134 \\
\hline Potassium (mmol/L) & 3.2 & 3.1 & 3.7 & 3.6 & 4.7 & 3.3 & 3.5 & 4 & 3.5 & 3.6 \\
\hline Chloride $(\mathrm{mmol} / \mathrm{L})$ & 104 & 106 & 106 & 104 & 108 & 103 & 102 & 98 & 100 & 101 \\
\hline Bicarbonate $(\mathrm{mmol} / \mathrm{L})$ & 24.9 & 26.1 & 28.1 & 31.1 & 30.3 & 28.7 & 27.4 & 26.1 & 25.9 & 24.2 \\
\hline Urea (mg/dL) & 34.5 & 37.8 & 35.2 & 43.6 & 50.9 & 47.1 & 35.7 & 31.2 & 41 & 29.9 \\
\hline Creatinine $(\mathrm{mg} / \mathrm{dL})$ & 0.9 & 1 & 0.8 & 0.5 & 0.4 & 0.4 & 0.4 & 0.4 & 0.5 & 0.4 \\
\hline $\mathrm{PT}(\mathrm{s})$ & 20.8 & & 19 & 18.2 & 16.1 & & & 21.6 & & \\
\hline INR (\%) & 1.82 & & 1.65 & 1.58 & 1.4 & & & 1.89 & & \\
\hline $\operatorname{APTT}(\mathrm{s})$ & & & 26.6 & 25.7 & 25.2 & & & 26 & & \\
\hline $\mathrm{Ca}(\mathrm{mg} / \mathrm{dL})$ & 7.23 & 8.02 & & 7.7 & 8.73 & 6.99 & 6.87 & 8.71 & 7.8 & 7.32 \\
\hline Albumin (g/dL) & 3.5 & 2.6 & 2.3 & 2.1 & 2.6 & & & 2.4 & 2.4 & 2.4 \\
\hline Total protein $(\mathrm{g} / \mathrm{dL})$ & 6 & 4.6 & & & & & & 4.5 & & \\
\hline Total bilirubin (mg/dL) & 0.49 & 0.42 & & & & & & 1.03 & & \\
\hline Direct bilirubin (mg/dL) & 0.14 & 0.14 & & & & & & 0.31 & & \\
\hline GGTP (U/L) & 103 & 58 & & & & & & 309 & & \\
\hline Alk.Po4 (IU/L) & 100 & 66 & & & & & & 191 & & \\
\hline SGPT (IU/L) & 35 & 15 & & & & & & 102 & & \\
\hline SGOT (IU/L) & 26 & 17 & & & & & & 35 & & \\
\hline TSH (mIU/L) & 14.55 & & 6.95 & & & 9.52 & & & & \\
\hline Triglyceride pleural (mg/dL) & & 334 & 43 & 364 & & & & 53 & & \\
\hline Triglyceride pericardial (mg/dL) & & 51 & 35 & & & & & & & \\
\hline Triglyceride blood (mg/dL) & & 129 & 121 & & & & & & & \\
\hline
\end{tabular}


Sharma, et al.: Right side chylothorax, lymphangiography

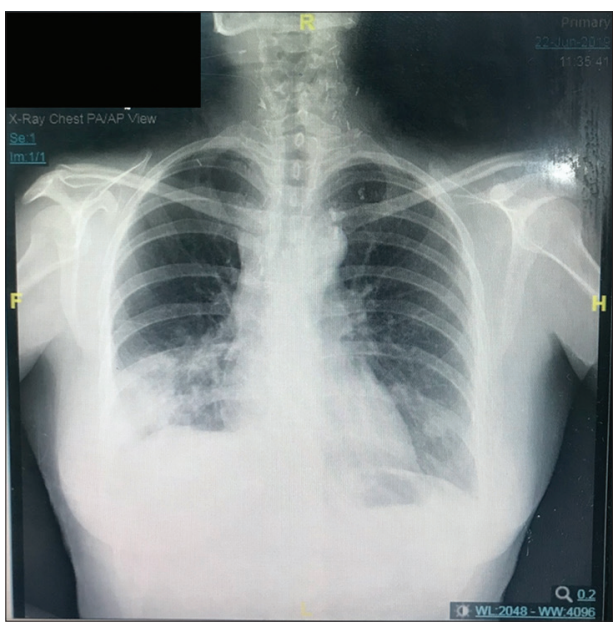

Figure 2: Chest X-ray (postlymphangiography) resolution of chylothorax

chyle formation, which may be accomplished with total parenteral nutrition (lipid free) and intravenous octreotide ${ }^{[3,4]}$ and is useful in low output $(<500 \mathrm{ml} /$ day $)$ chylous drain. As the resolution of chylothorax may take up to 8 months, therapeutic drainage with the relief of respiratory symptoms is the first step of management. However, up to $25 \%$ of patients may require surgical intervention in addition to conservative management.

Another approach after failed conservative management is radiological intervention involving TDL and thoracic duct embolization (TDE) ${ }^{[5]}$ Although TDE is more successful as compared to TDL, it is more invasive and a reported rate of success of $90 \%$. Conventional lymphangiography is an old and valuable tool which opacifies the lymphatic channels and therefore helps in the detection of lymphatic fistulas or lymphatic leakage. ${ }^{[6,7]}$ The success of TDL depends on the output of fistulas. It is successful in $70 \%$ of cases with lymphatic outflow $<500 \mathrm{ml} /$ day, but in patients with high output fistulas, its success rate is only $34.8 \%{ }^{[7,8]}$ As it is less invasive and easy to perform, it can be considered before opting for surgical interventions.

\section{Conclusion}

Isolated right chylothorax may be a rare complication of total thyroidectomy. Conservative therapy may be useful in low output fistulas. However, TDL may also be tried as a safe and viable therapeutic option in the management of high output fistulas before considering surgical options.

\section{Declaration of patient consent}

The authors certify that they have obtained all appropriate patient consent forms. In the form, the patient has given her consent for her images and other clinical information to be reported in the journal. The patient understands that name and initials will not be published, and due efforts will be made to conceal identity, but anonymity cannot be guaranteed.

\section{Financial support and sponsorship}

Nil.

\section{Conflicts of interest}

There are no conflicts of interest.

\section{RefERences}

1. Merki V, Pichler J, Giger R, Mantokoudis G. Chylothorax in thyroid surgery: A very rare case and systematic review of the literature. J Otolaryngol Head Neck Surg 2016;45:52.

2. Schild HH, Strassburg CP, Welz A, Kalff J. Treatment options in patients with chylothorax. Dtsch Arztebl Int 2013;110:819-26.

3. Schild HH, Pieper C. Chylothorax: Current therapeutic options. Zentralbl Chir 2019;144:S24-30.

4. Swanson MS, Hudson RL, Bhandari N, Sinha UK, Maceri DR, Kokot N. Use of octreotide for the management of chyle fistula following neck dissection. JAMA Otolaryngol Head Neck Surg 2015;141:723-7.

5. Patel N, Lewandowski RJ, Bove M, Nemcek AA Jr., Salem R. Thoracic duct embolization: A new treatment for massive leak after neck dissection. Laryngoscope 2008;118:680-3.

6. Alejandre-Lafont E, Krompiec C, Rau WS, Krombach GA. Effectiveness of therapeutic lymphography on lymphatic leakage. Acta Radiol 2011;52:305-11.

7. Jeong H, Ahn HY, Kwon H, Kim YD, Cho JS, Eom J. Lymphangiographic interventions to manage postoperative chylothorax. Korean J Thorac Cardiovasc Surg 2019;52:409-15.

8. Guermazi A, Brice P, Hennequin C, Sarfati E. Lymphography: An old technique retains its usefulness. Radiographics 2003;23:1541-58. 